\title{
Reseña de Richard Parra, La tiranía del Inca. El Inca Garcilaso y la escritura política en el Perú colonial (1568-1617), Lima, Ediciones Copé, 2015, 508 pp., ISBN 978-6124-20-221-6
}

\author{
Germán Morong Reyes \\ Centro de Estudios Históricos \\ Universidad Bernardo O'Higgins \\ CHILE \\ german.morong@ubo.cl
}

[Hipogrifo, (issn: 2328-1308), 4.1, 2016, pp. 293-297]

Recibido: 14-03-2016 / Aceptado: 30-03-2016

DOI: http://dx.doi.org/10.13035/H.2016.04.01.20

La tiranía del Inca fue una construcción política y jurídica que se originó desde la llegada de las huestes de Francisco Pizarro al Perú en 1532. Desde esa temprana fecha y con una progresiva retórica que debatía sobre el carácter de ilegitimidad o de legitimidad de los gobernantes cusqueños - colmada de cierta furia colonialista- los Incas pasaron a constituirse en un objeto predilecto en la prosa de cronistas, funcionarios reales y clérigos hasta la construcción de un verdadero corpus documental sobre el carácter «ilegal» de su presencia en los Andes prehispánicos, desarrollado con fruición en las décadas de 1560 y 1570. La historiografía y etnohistoria del Perú colonial ha contextualizado esta producción escritural al advenimiento del quinto virrey del Perú Francisco de Toledo (1569-1581), siendo la Historia General Llamada Índica de Pedro Sarmiento de Gamboa (1572) y el Parecer de Yucay (1571) las vigas maestras por las cuales el virrey justificó no solo la «ilegalidad» de los incas en tiempos prehispánicos, sino el descabezamiento de su último representante Tupác Amarú I en 1572.

Richard Parra, desde la crítica literaria, nos entrega esta obra que permite sintetizar -con prosa especializada- los alcances analíticos que permite la ardua discusión que fue generándose en torno a la «tiranía incaica», a partir de la sistemática intervención centralista operada con la ascensión de Felipe II al poder en 1556. Se trata de su tesis doctoral defendida en diciembre de 2012 en la Universidad de Nueva York con el título original de La tiranía del Inca: el humanismo del Inca Garcilaso y la escritura política en el Perú colonial (1568-1617). Como bien es sabido, en esta larga polémica de implicancias jurídicas y políticas concretas 
el Inca Garcilaso fue el difusor mas conocido de la llamada «utopía incaica», al promover en los círculos letrados castellanos la idea de un gobierno prehispánico justo y generoso, capaz de rastrear el conocimiento del verdadero Dios. Al unísono, sometía a un duro juicio la política del virrey Toledo destinada a legitimar la imagen repulsiva del estado incaico. Las implicancias, por ejemplo, de los Comentarios reales (1608) tuvieron clara repercusión más tarde en la noción de restitución del incario operada en los bandos rebeldes emitidos por Tupác Amaru II en 1781. Siendo la figura de Garcilaso de la Vega un tema de estudio que tiene la carga ineludible de la inmensa producción precedente que ha constituido su obra como objeto de estudio, es meritoria la aproximación renovada que implica la exégesis con que ha sido abordado. En este sentido, el autor nos invita a leer a Garcilaso en su totalidad, es decir, no solo a releerlo desde la historiografía -asumiendo su crónica en tanto relato de hechos para una tarea de carácter reconstructivo- sino como un escritor de la modernidad muy consciente de su arte literario, cuyo sentido último dice relación con el rescate de una memoria histórica reivindicativa que debe ser mantenida en el periplo colonial.

El texto esta dividido en cuatro partes y siete capítulos desarrollados con prosa amena y pedagógica. Inicia con un interesante prólogo de Luis Millones de Santa Gadea, conocido andinista, quién valora la audacia de retomar a un escritor que ha hecho fortuna en los círculos académicos europeos y americanos. Millones aporta con una breve genealogía sobre los estudios dedicados a Garcilaso, ensayando un análisis comparativo de los Comentarios reales con las crónicas y memoriales que imputan a los incas el carácter de tiranos, textos elaborados bajo la atenta mirada del virrey Toledo. En la sección introductoria, el autor delimita el marco teórico y las coordenadas analíticas a través de las cuáles enfrentará no sólo los textos de Garcilaso (Comentarios reales, La florida del Inca y la traducción de los Diálogos de amor de León Hebreo), sino el corpus documental enmarcado en dos frentes ideológicos claros; la retorica disidente de los jesuitas Luis López, Blas Valera y Jesuita anónimo que promueve una defensa acérrima al orden incaico y la artificiosa retórica de Pedro Sarmiento de Gamboa y Juan de Matienzo que invalidan la presencia de un estado prehispánico sujeto al derecho natural. El autor -utilizando rejillas de lectura como colonialismo, imperialismo, sujeto colonial y escritura transculturalcontextualiza el debate sobre la legitimidad de la conquista y, consecuentemente, la emergencia arbitraria de una descripción generalizada de los incas como «tiranos» en el debate indiciario operado por Las Casas y Sepúlveda en 1551. Para Richard Parra en el virreinato del Perú «hubo un discurso colonial que asumió la teoría imperialista de Sepúlveda y otro el reformismo misionero de Las Casas» (pp. 38-39). Estos discursos cobrarán valor y serán recreados durante el gobierno toledano y una vez muerto Las Casas en 1566. El autor da una importancia gravitante al quinto virrey en el sentido que cumplió una función axial en la «configuración de la estructura, ideología y escritura de los textos aquí estudiados» (p. 39). Un argumento central, desarrollado en esta parte, es la convicción de que los textos en comento (Garcilaso, Sarmiento, Matienzo, López, Anónimo, Blas Valera, etc.) «emergieron de la experiencia de la violencia y generaron, ante ella, proyectos de reordenamiento, 
de protesta y de justicia» (p. 39). Las preguntas de investigación implican los supuestos precedentes, a saber:

¿Qué importancia histórica y literaria tuvo el debate sobre la tiranía de los incas en la cultural colonial?, ¿Qué intereses concretos determinaron la discusión sobre la tiranía de los incas?, ¿Qué tradiciones intelectuales y retóricas se emplearon en dicho debate?, ¿La crítica a Toledo conformó una nueva tradición letrada? y en el caso de Garcilaso, ¿su negación de la tiranía de los incas produjo un discurso de resistencia? (p. 39).

Todo ello articula la redacción de los capítulos posteriores.

La primera parte de la obra en comento, titulada «Creando la tiranía de los Incas», implica la consideración y análisis de dos secuencias narrativas problemáticas al servicio de la fiscalidad colonial (cap. I y II) que inscriben en los incas la condición de perversos tiranos. El capítulo I, «Algunas nociones sobre tiranía (de Platón a Matienzo)», establece de forma general la definición del término tiranía, tomando como referencias de autoridad los tratados de Platón, Aristóteles, Tomás de Aquino, Francisco de Vitoria y Bartolomé de Las Casas. Revisa también las nociones quechuas de «capac» y «auca» vinculadas al ejercicio político de gobierno. Culmina este capítulo exponiendo el plan retórico de Juan de Matienzo en su conocido Gobierno del Perú (1567), que sirve para sintetizar, a través de su obra, los postulados esenciales de la tradición clásica respecto al orden tiránico (con énfasis en Aristóteles y Platón). En el contexto de la turbulenta década de 15601570, Matienzo - junto a Polo Ondegardo - se transforma en defensor acérrimo del derecho natural impugnando la tesis lascasiana de un señorío natural prehispánico (caciques e incas) que habría sido usurpado por la presencia hispana. Revirtiendo este contundente argumento, propiciado por muchos eclesiásticos, el oidor de Charcas reafirma la idea de que fueron precisamente los incas $-y$ los curacas puestos por los primeros - los que violaron una primigenia ley natural al usurpar el poder de los señores naturalmente constituidos. El capítulo II, «Narrando la tiranía: la Historia Índica de Pedro Sarmiento de Gamboa (1572)», expone claramente el relato de un clásico respecto a la impugnación de una tiranía prehispánica. Junto al Parecer de Yucay (1571), la Historia General Llamada Índica propone una historia genealógica de los gobernantes cusqueños transformados en viles tiranos. El valor que Toledo le daría a esta obra -que el mismo encomendó al cronista y cosmógrafo- está sustentado en el procedimiento etnográfico operado a través de la legitimación de los mismos nobles cusqueños sobre la información que se les leía. Esto es, que los propios indios señalaron la «veracidad» del relato de Sarmiento. La historia índica es signada como la primera historia verídica, nunca antes creada, sobre la base de un procedimiento historiográfico exhaustivo y legitimado por las autoridades virreinales. Todo ello, con el propósito de «contrarrestar la potencial amenaza a los españoles por algún heredero Inca y el resurgimiento de un movimiento eclesiástico contrario a sus proyectos» (p. 110).

La segunda parte, «La silenciada protesta jesuita» que incluye el cap. III «Responder y contradecir: escritura jesuita contra el virrey Toledo», es un intento docu- 
mentado de analizar la prosa refractaria al colonialismo que intentan los jesuitas Luis López, Blas Valera y Jesuita anónimo. El autor precisa que los jesuitas negaron la tiranía de los incas, creando al unísono una imagen de aquellos como potenciales cristianos. Esta posición, a favor de estos últimos, los enfrentó directamente con el virrey Toledo. En este sentido, el proyecto jesuita planteó una crítica escolástico-legal a las políticas virreinales al considerar un pasado histórico ideal de los incas y la posibilidad certera de que su gobierno y la conformación de su imperio se efectuó por la vía de la persuasión y no por la guerra. Siguiendo al autor, el proyecto jesuita inscribió en los círculos letrados la idea generalizada de un buen gobierno incaico, paternalista y colectivista. Esta retórica «pro-inca» sentaría a la sazón una verdadera tradición crítica anticolonialista. En esta parte, se echa de menos la incorporación de otro corpus documental vinculado a la retórica de los domínicos y franciscanos, que de forma previa ya había sostenido al incanato como modelo de gobernabilidad; es el caso de un ausente en este libro, el licenciado Francisco Falcón (1521-1587).

En la tercera parte, «El humanismo crítico de León Hebreo y el Inca Garcilaso» que incluye los capítulos IV («Tiranía y alegoría: León Hebreo y Garcilaso») y V («Ejemplaridad y tiranía en La florida del Inca») el autor conecta la influencia neoplatónica de León Hebreo (Diálogos de amor) en los Comentarios reales. En esta última obra Garcilaso le otorga a los incas «un nivel intelectual y religioso categóricamente superior al que hasta ese momento les había otorgado la cultura colonial del conquistador» (p. 234). El autor sostiene que Garcilaso dotó de nuevos capitales culturales a los incas como civilización, a saber: «narrando la supuesta ejemplaridad de los indios de la Florida o, luego, la transformación de Atahualpa de tirano a un virtuoso gobernante capaz de cuestionar el mismísimo derecho de conquista de los europeos» (p. 235). La síntesis a la que arriba Parra es que el proyecto de Garcilaso, leído a través de León Hebreo, plantea que la reconstrucción históricofilosófica de la política incaica «sirvió para subrayar el sentido civilizatorio de los incas y para afirmar una legitimidad capaz de contrarrestar lo que planteaba con vehemencia el proyecto toledano: una latente bastardía -en el sentido expuesto por Hebreo- de los últimos incas» (p. 236).

Una última parte, «El anticolonialismo del Inca Garcilaso», contiene los dos últimos capítulos del libro. En el capítulo VI («La escritura de resistencia de Garcilaso en los Comentarios reales de los incas») y VII («De tirano a virtuoso: la transformación de Atahualpa en la segunda parte de los Comentarios reales de los incas»), Richard Parra analiza la obra capital del escritor mestizo a partir de una serie de autores dedicados previamente al análisis de los Comentarios (como Rabasa, Mazzotti, Cornejo Polar, entre otros). Las conclusiones evidentes de este pormenorizado análisis es el argumento de que en el cronista opera una subversión de los valores de la conquista y un proyecto bien elaborado de resistencia (idea largamente trabajada por la crítica literaria y la historiografía). Uno de los elementos de tal subversión es la legitimidad que otorga a la tradición oral cusqueña al transformarla en una escritura que funge de correlato a la versión oficial promovida con fruición por Toledo. Las incidencias de la producción de tal discurso reivindicativo servirán de base para la formación de una «identidad nacional» peruana, al advenimiento de 
las rebeliones anti-fiscales ad portas a los procesos de independencia a fines del siglo XVIII. Promueve, asimismo, una versión alterna de los hechos ocurridos en Cajamarca transformando el relato justificativo de la conquista en un discurso de resistencia que indica con claridad el nivel de violencia y la masacre practicada por las huestes de Pizarro.

Con todo, estamos frente a una obra que logra analizar -en tanto intertextualidad - un conjunto significativo de textos que se propusieron objetivar al Inca y su modelo político a la luz de una tradición epistemológica humanista/renacentista, heredera indiscutida de los textos clásicos. A su vez, permite contextualizar el escenario ideológico del Perú colonial del siglo XVI y los frentes discursivos que se instalaron al servicio de la sujeción colonial o al servicio de la prosa eclesiástica no exenta de sus propios intereses doctrinarios. Dejamos al lector ponderar la contribución que nos ofrece Richard Parra. 
